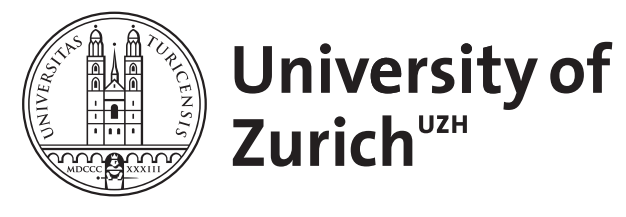

\title{
Protein kinases controlling the onset of mitosis
}

\author{
Ferrari, S
}

\begin{abstract}
This review article focuses on protein kinases regulating the onset and transition through mitosis. The essay begins by introducing the structural features of the protein kinase catalytic domain and emphasizing the mechanism of enzymatic activation of this class of proteins. Next follows a short historical perspective on cell division and a description of our current understanding of mitosis. In the central part of the review I examine the four major kinases that set the stage for mitosis, which consist of Cdk1, Polo-like 1, Nek2 and Aurora kinases. For each entry dealt with, I focus particularly on studies that have linked DNA damage response pathways to inhibition of kinase activity, and I evaluate the conclusions drawn. Finally, I examine protein kinases initially described in the context of different cell cycle transitions and only later proposed to be involved in the control of mitosis.
\end{abstract}

DOI: https://doi.org/10.1007/s00018-005-5515-3

Posted at the Zurich Open Repository and Archive, University of Zurich ZORA URL: https://doi.org/10.5167/uzh-34286

Journal Article

Published Version

Originally published at:

Ferrari, S (2006). Protein kinases controlling the onset of mitosis. Cellular and Molecular Life Sciences, $63(7-8): 781-795$.

DOI: https://doi.org/10.1007/s00018-005-5515-3 


\title{
Review
}

\section{Protein kinases controlling the onset of mitosis}

\author{
S. Ferrari \\ Institute of Molecular Cancer Research, University of Zurich, Winterthurerstrasse 190, 8057 Zurich (Switzerland), \\ Fax: +41 44635 3484, e-mail: sferrari@imcr.unizh.ch
}

Received 26 October 2005; received after revision 1 December 2005; accepted 5 December 2005

Online First 7 February 2006

\begin{abstract}
This review article focuses on protein kinases regulating the onset and transition through mitosis. The essay begins by introducing the structural features of the protein kinase catalytic domain and emphasizing the mechanism of enzymatic activation of this class of proteins. Next follows a short historical perspective on cell division and a description of our current understanding of mitosis. In the central part of the review I examine the four major kinases that set the stage for mitosis, which
\end{abstract}

consist of Cdk1, Polo-like 1, Nek2 and Aurora kinases. For each entry dealt with, I focus particularly on studies that have linked DNA damage response pathways to inhibition of kinase activity, and I evaluate the conclusions drawn. Finally, I examine protein kinases initially described in the context of different cell cycle transitions and only later proposed to be involved in the control of mitosis.

Keywords. Phosphorylation, protein kinase structure, mitosis, DNA damage, checkpoint.

\section{Protein phosphorylation}

The year 2003 marked the 50th anniversary of the elucidation of the double helical structure of DNA. The following year marked another important 50th anniversary: the discovery of protein phosphorylation [1]. It is paradigmatic that when phosphorylation was initially described $[2,3]$ in relation to the metabolism of glycogen [4], it was believed to be limited to the regulation of this single pathway. Far from being true, subsequent studies have proven the universal use of phosphorylation in the control of cellular metabolism, cell cycle transitions, growth, differentiation and apoptosis. Enzymatic phosphorylation has proven to be the most rapid and versatile reversible post-translational modification of proteins affecting activity, localization, stability and protein-protein interactions. Phosphorylation is controlled by protein kinases, which transfer a phosphate group from the donor ATP or GTP onto acceptor amino acids in the substrate protein, and protein phosphatases that catalyze hydrolysis of the phosphoester bond and release of free phosphate.
To facilitate understanding of the subject dealt with in this review, I will first introduce the key structural features of the protein kinase family and then discuss the mechanisms controlling the activity of kinases involved with the onset of mitosis. For a detailed account of kinases involved in other aspects of mitosis, the reader is referred to specialized literature [5-7].

\section{Protein kinase phylogeny and structure}

Identification of the first kinases was followed by intense work focused on the clarification of enzymatic properties. It was not until the mid-1970s, when techniques such as cloning by homology and the polymerase chain reaction (PCR) were introduced, that the incessant discovery of novel members of the kinase family prompted the first attempt of aligning the catalytic domain of 65 distinct eukaryotic protein kinases (ePKs) [8]. Although this pioneering work was carried out using a wordprocessor, it nevertheless provided a first glimpse of the complexity of 
this family of enzymes and prompted attempts to estimate its size [9]. The most recent kinase phylogenetic tree, obtained with today's sophisticated software, fully accounts for the complexity of the protein kinase family and shows that early predictions of the number of kinases present in the genome were not too far off. Current classifications encompass all protein kinases identified upon conclusion of the first draft sequencing of the human genome, which include $478 \mathrm{ePKs}$ and about 40 aPKs (atypical protein kinase) genes. PK genes account for $\sim 2 \%$ of all human genes.

ePKs are distinct from histidine kinases and other phosphotransfer enzymes [10], share a conserved catalytic domain but greatly differ in the mechanisms controlling activity. Conversely, aPKs present no obvious similarity to the ePK catalytic domain that would allow their annotation as protein kinases [11], but possess kinase activity that can be demonstrated in biochemical assays. The most recent classification of protein kinases, which is still based on the comparison of catalytic domains, yielded nine major groups, 134 families and 189 subfamilies

a
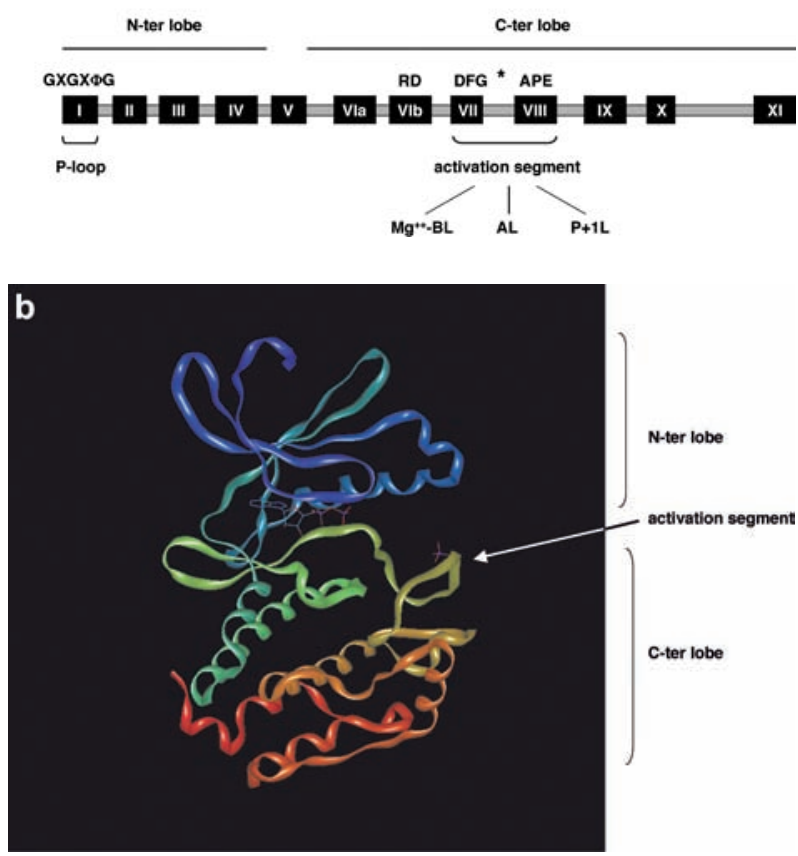

Figure 1. Structure of protein kinases' catalytic domain. (a) The core catalytic domain of protein kinases encompasses 12 subdomains I-IV and VI-XI, participate in the formation of the bi-lobate structure of protein kinases. Conserved residues in the P-loop and in the activation segment are shown. The asterisk represents the position of residue(s) in the activation segment the phosphorylation of which triggers kinase activation (see text for the details). $\mathrm{Mg}^{++}-\mathrm{BL}$, $\mathrm{Mg}^{++}$- binding loop; $\mathrm{AL}$, activation loop; $\mathrm{P}+1 \mathrm{~L}, \mathrm{P}+1$ loop. (b) $3 \mathrm{D}$ structure of Aurora A catalytic domain (PBD ID: 1MQ4 [191]). The ATP bound in the deep cleft between N- and C-terminal lobes and the residue phosphorylated in the activation segment are shown.
[11]. Most of the kinase families found in the genome of Homo sapiens are also present in other metazoans such as yeast, worm and fly. Human kinases are, however, twice as many as in the fly or worms [12]. The higher complexity of the human kinome is accounted for by expansion of families whose members control processes that are more developed in higher metazoans, such as haematopoiesis, angiogenesis and immunity [12]. About $10 \%$ of all ePKs were found to lack key residues involved with catalysis. This led to the hypothesis that expression of inactive kinases may either serve a scaffolding function or be in place to regulate the activity of neighboring catalytic domains in cis [11].

From a structural point of view, the ePK catalytic domain comprises 12 sub-domains containing highly conserved amino acid residues (Fig. 1a). All ePKs display a similar fold which is reminiscent of the structure of a ribosome: they consist of an $\mathrm{N}$-terminal lobe, predominantly composed of $\beta$-sheets and one single $\alpha$-helix called the C-helix, and a larger $\mathrm{C}$-terminal region that is essentially made up of $\alpha$-helices [13] (Fig. 1b). The amino-terminal lobe encompasses subdomains I-IV, whereas the carboxy-terminal lobe contains subdomains VI-XI (Fig. 1a). The interface between the two lobes forms a deep cleft which accommodates ATP [13] (Fig. 1b). Bound ATP is capped by a glycine-rich motif called phosphate loop or P-loop, located in subdomain I and displaying the conserved motif GXGX $\Phi \mathrm{G}$, where $\Phi$ is in most cases a hydrophobic amino acid [8]. Access to the ATP-binding site in many kinases is obstructed by a peptide that is located between the conserved motifs DFG and APE in subdomains VII and VIII (Fig. 1a). This region is called the activation segment, is generally $20-30$ residues in length and contains one or two sites of phosphorylation that are critical for activation in many kinases [13]. Structural studies have shown that in most kinases, phosphorylation of the activation segment leads to repositioning of this loop, which, as result, assumes an extended conformation and can interact with the substrate [14] (Fig. 1b). Mechanistically, the conformational change that stretches the activation segment is facilitated by ionpairing between the phosphorylated residue in the activation segment and an arginine that in many cases precedes the catalytic aspartate in subdomain VIb (RD di-peptide) [15] (Fig. 1a). In addition to a role in repositioning the activation segment, such interaction was proposed to neutralize the arginine's positive charge that would otherwise hamper catalysis by the neighboring aspartate $[13,14]$. Structurally, the activation segment comprises three elements, the $\mathrm{Mg}^{++}$-binding loop, the activation loop and the $\mathrm{P}+1$ loop [16] (Fig. 1a). The first is involved in chelating the $\mathrm{Mg}^{++}$-ATP complex, whereas the second physically contains the site(s) of regulatory phosphorylation. The sequence of amino acids flanking the activation loop normally defines the consensus for 
recognition of this particular loop and ensuing phosphorylation by upstream kinase(s). In addition to its role in the process of kinase activation, the activation loop has been shown to be involved in a less-explored but equally important mechanism: this is the interaction with proteins that affects the localization and activity of a protein kinase [17]. Finally, the $\mathrm{P}+1$ loop located at the extreme $\mathrm{C}$-terminus of the activation segment has a critical function in substrate binding. This loop was named after its ability of contacting the $\mathrm{P}+1$ residue in the peptide inhibitor PKI bound to protein kinase A (PKA), though it is now evident that the $\mathrm{P}+1$ loop interacts with additional neighboring residues [16]. The primary structure of regions located outside the catalytic domain of serine/threonine kinases varies extremely and encompasses domains involved in regulatory functions, protein-protein interaction modules and motifs controlling subcellular localization $[10,11]$.

\section{Mitosis}

The first description of a cell was made by the English physicist Robert Hooke (1635-1702), who observed the structure of cork slices with one of the early microscopes [18]. In 1838 and 1839, two German scientists, the botanist Matthias Jakob Schleiden (1804-1881) and the physiologist Theodor Schwann (1810-1882), proposed that cells are the basic units of all organisms and that the nucleus may have an important role in the genesis of cells, although the latter concept was not correctly formulated. In 1852 the eminent pathologist Robert Remak (1815-1865), reporting his observations on frog eggs, concluded that cleavage is due to a continuous process of division that always begins with the nucleus. In 1858 Rudolf Virchow (1821-1902) formally formulated the principle that every cell derives from a pre-existing cell: 'omnis cellula e cellula'. Finally, Theodor Boveri (1862-1915), working on the eggs of Ascaris megalocephala, a parasitic worm containing only four chromosomes, was the first to describe the behavior of chromosomes during cell division [19] (see also: http://www.laskerfoundation.org/news/gnn/timeline/). Thanks to the identification of suitable model organisms and with the help of modern technology, we have now reached a deep understanding of mechanistic aspects and regulatory pathways controlling the onset, execution and completion of mitosis [20]. According to the current view, mitosis is composed of five phases: prophase, prometaphase, metaphase, anaphase and telophase. Upon completion of DNA replication, sister chromatids are held together at the centromeric region by structures called kinetochores and are catenated through their entire length by cohesins [21]. The first event clearly visible in prophase nuclei is chromatin con- densation, which allows reducing the length of uncondensed DNA to an extent compatible with the distance that chromatids cover when moving to the opposite poles of the mitotic spindle [22]. Chromatin condensation requires the combined action of a multisubunit protein complex named condensin and of topoisomerase II, the latter being involved in the decatenation of sister chromatids [22]. Chromatin condensation coincides with phosphorylation of histone $\mathrm{H} 3$, a process that depends on the activity of the kinase Aurora B (see below). In late prophase, the microtubuli that formed the interphase cytoskeleton are disassembled, and highly dynamic microtubules radiate from centrosomes. These mitotic microtubules drive the migration of separated centrosomes, each with its pair of centrioles, to the opposite poles of the cell. Nuclear envelope breakdown, which is facilitated by phosphorylation of lamins, ensues at the time of transition to prometaphase. At this point, spindle microtubules enter the nucleus and make contact with kinetchores that are located on each chromatid and face to opposite directions. As the cell approaches metaphase, chromosomes congress to the equator of the spindle where they are aligned to form the so-called metaphase plate. This process may require a substantial amount of time, since complete assembly of the mitotic spindle implies that all kinetochores attach to fibers that have nucleated from the two opposite centrosomes (a process called bi-orientation). At anaphase, the movement of chromatids to the poles of the spindle results from shortening of the microtubules that are attached to kinetochores. At the molecular level, the separation of chromatids is facilitated by anaphase-promoting-complex/cyclosome (APC/C)-driven degradation of cohesin [23]. Concomitant with disassembly of kinetochore microtubules, the elongation of polar microtubules contributes to push the spindle poles aside. The process is concluded by re-establishment of the nuclear membrane around decondensing chromosomes at telophase and is followed by physical separation of the two daughter cells, or cytokinesis [24].

\section{Cyclin-dependent kinase 1}

The prototype cyclin-dependent kinase $\mathrm{Cdc} 2$, now known as Cdk1, belongs to the CMCG group [11] and was discovered through convergence of genetic and biochemical studies. Paul Nurse, studying the cell division cycle in yeast, identified genes exerting cell size control at nuclear division [25]. Biochemical investigations carried out on amphibian oocytes a few years earlier $[26,27]$ led to the identification of MPF, or maturation-promoting factor, a factor that was shown to facilitate entry into mitosis and meiosis. In 1988, working with Xenopus oocytes, Lohka and co-workers successfully purified 
MPF [28], which turned out to be composed of Cdk1 [29$32]$ and a B-type Cyclin $[33,34]$. The Cdk1 protein is constantly present throughout the cell division cycle, but its activity is finely tuned by means of protein-protein interactions and reversible phosphorylation [35]. The two regulatory partners of Cdk1 are Cyclin A and Cyclin B, which are encoded by genes that are under cell cycle-dependent transcriptional control $[36,37]$. Prior to cyclin binding, Cdks are in an inactive conformation with the Chelix of the small lobe (also called PSTAIRE after its primary sequence) pointing outward, in a position that excludes the last residue of the helix, the catalytic $\mathrm{E}_{51}$, from the active site [38]. Interaction with cyclin occurs over a large surface and facilitates repositioning of the PSTAIRE helix in a way that brings $\mathrm{E}_{51}$ in close proximity to $\mathrm{K}_{33}$, the residue that coordinates ATP. Such conformational modification is, however, not sufficient to confer full activation on Cdk. Rather, activation results from phosphorylation of a residue in the activation loop ( $\mathrm{T}_{161}$ or $\mathrm{T}_{160}$ in Cdk1 or Cdk2, respectively) by an upstream kinase known as Cdk-activating kinase (Cak) [39, 40]. Phosphorylation at this residue is cell cycle-regulated in a manner that parallels the pattern of cyclin binding [41] and results in ion-pairing of the T-loop $\mathrm{T}_{161}$ with $\mathrm{R}_{128}$, a residue that precedes the catalytic $\mathrm{D}_{129}$. This interaction neutralizes the positive charge of $\mathrm{R}_{128}$ and facilitates repositioning of the activation loop that allows now binding of the substrate (see above) [13]. Cdk1 isoforms lacking most of the T-loop are present in breast cancer cells but not in normal fibroblasts and lymphocytes [42]. Tloop deletion mutants were reported to be unable to interact with cyclin B1 and displayed no kinase activity, thus pointing to the important function of the T-loop in protein-protein interaction in addition to its role in facilitating catalysis [42].

A second layer of control on Cdk1 activity is exerted by signals delivered by the machinery that detects completion of DNA synthesis and/or successful repair of damaged DNA (Fig. 2). Such signals converge on the kinases Wee-1 and Myt1 that inhibit Cdk1 kinase activity through phosphorylation of two residues, $\mathrm{Thr}_{14}$ and $\mathrm{Tyr}_{15}$, in the Gly-rich P-loop. Initial studies led to the proposal that phosphorylation at these sites would impair ATP binding, either sterically and/or by electrostatic repulsion [43]. However, a later assessment of the mechanism of Cdk1 inhibition revealed that phosphorylation at these sites did not affect nucleotide binding but rather hampered catalysis [44]. $\mathrm{Thr}_{14}$ and $\mathrm{Tyr}_{15}$ are dephosphorylated by the dual-specificity phosphatase Cdc25C [45], the activity of which increases during mitosis and is triggered through Cdk1- [46] and Polo-like kinase 1-dependent phosphorylation [47] (Fig. 2). A mechanistic model accounting for the effect of phosphorylation of P-loop residues on the inhibition of catalytic activity was formulated upon resolution of $\mathrm{Cdk} 2$

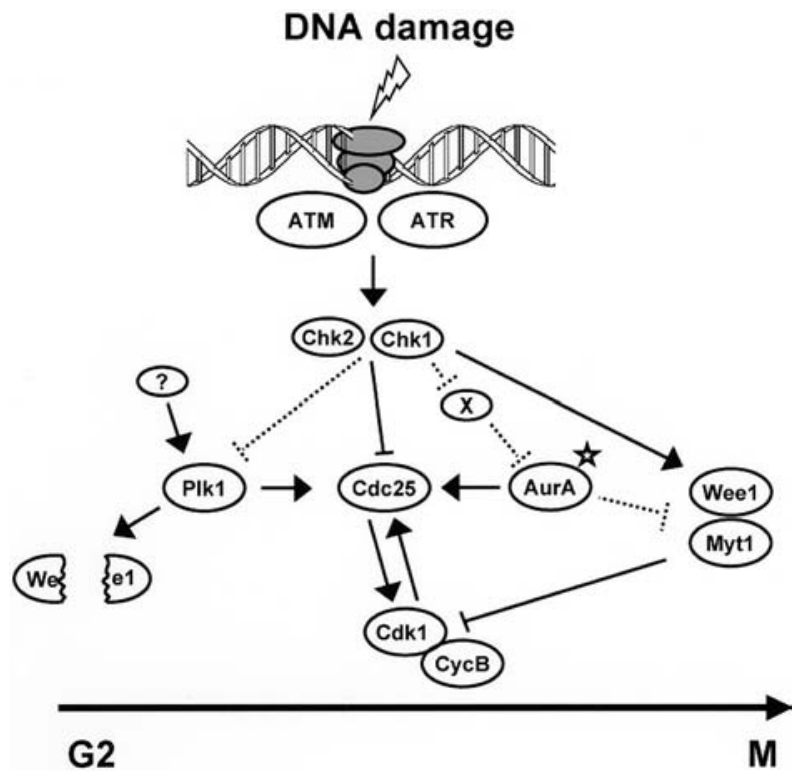

Figure 2. The G2/M DNA damage checkpoint. Detection of double-strand breaks in DNA by protein complexes (depicted in grey) sensing damage is followed by initial processing of the lesions. This generates structures that trigger DNA damage checkpoints. The G2/M checkpoint controls key components of the mitotic machinery such as Cdk1, Plk1 and AurA and results in arrest before the onset of mitosis. Hyperactivation of oncogenes such as AurA (indicated by a star) may facilitate bypass of the checkpoint in the presence of unrepaired damage, whereas reactivation of Plk1 through an as yet unknown mechanism (indicated by a question mark) may contribute to DNA damage recovery. Solid lines represent established control mechanisms, whereas dotted lines indicate hypothetical links.

crystal structure [48]. According to the latter, the hydroxyl group of $\mathrm{Thr}_{14}$ and $\mathrm{Tyr}_{15}$ point inward the ATPbinding site in a manner that brings them in close proximity to ATP, particularly in the case of $\mathrm{Thr}_{14}$. In Cdk2, the phosphates of ATP are normally held in place by interaction with a number of residues involved with catalysis, among which $\operatorname{Lys}_{33}$ and $\mathrm{Asp}_{145}$, and backbone amides of the P-loop [48]. Phosphorylation of P-loop residues was suggested to disrupt the conformation of the phosphates of ATP and, as such, impair catalysis [48]. Given the high homology between $\mathrm{Cdk} 2$ and $\mathrm{Cdk} 1$, the model is likely extendable to the latter.

The influence of Cdk1 on mitotic entry has been established through genetic studies in model organisms [4953], microinjection experiments [54, 55], expression of a dominant-negative mutant isoform [56], induced expression of cyclin-dependent-kinase inhibitors (CKI) [57, 58] and the use of chemical inhibitors (reviewed in [59]) and have been extensively reviewed elsewhere [60]. The mechanisms through which Cdk1 promotes entry and transition through mitosis are multiple and are mediated by phosphorylation of numerous substrates. These include lamins, the phosphorylation of which leads to nuclear membrane breakdown [61], microtubule-associ- 
ated proteins and kinesin-related motor proteins, which participate in centrosome separation and assembly of the mitotic spindle [62], and proteins that control chromosome condensation such as condensins [63]. In addition to the supervision of mechanistic aspects of mitosis, Cdk1 fulfills a regulatory function through the control of the anaphase-promoting-complex/cyclosome (APC/C) $[64,66]$, a protein destruction machinery that sets the timing of transition through and exit from mitosis by degrading cyclins, Polo-like kinase 1, Aurora-A and -B, Nek2, securin and Cdc20 among others (reviewed in [67]).

\section{Polo-like kinase 1}

Polo-like kinase 1 (Plk1) was initially identified in Drosophila as a kinase the mutation of which led to the formation of abnormal spindles [68]. The same phenotype was observed in yeast upon deletion of the Saccharomyces cerevisiae homologue (CDC5) [69]. Vertebrates express three to four members of the Polo family of kinases (reviewed in [70]), with Plk1 being the most extensively investigated component. Structurally, Plk1 is characterized by an N-terminal catalytic domain, a central destruction motif (D-box) and two polo box domains (PBDs) at the C-terminus. The PBD is capable of recognizing and binding phosphorylated residues in the context S-pS/pT-P/X [71], thus allowing Plk1 to dock to proteins that are in turn phosphorylated by Plk1. Considering that the consensus for PBD binding fulfills the requirements for phosphorylation by Proline-directed kinases such as Cdks and MAP kinases, it has been suggested that the latter may act as priming factors for Plk1 targeting [70].

The PBD has two established functions: it constitutes an autoinhibitory domain [72] whose negative role is relieved through phosphorylation at the T-loop site $\mathrm{T}_{210}$ [73] (see below), and it plays an important role in Plk1 subcellular localization [74]. The latter was elucidated in complementation studies conducted on the temperaturesensitive $c d c 5-1$ mutant yeast strain, where mutation of conserved residues in the PBD disrupted localization and mitotic functions of human Plk1, without nonetheless altering catalytic activity [75]. As support to this conclusion, evidence obtained by impairing PDB-mediated binding of Plk1 to its targets via introduction of competing phosphopeptides in cells, prevented Plk1 localization at centrosomes [71].

The $S$. cerevisiae Cdc5p and the mammalian homologue Plk1 are principally expressed in G2 and M phase [76, 77]. As for Cdc5p, activation of human and Xenopus Plk1 involves phosphorylation at two residues, one of which is located in the activation loop [78, 79]. Mutation of both sites to acidic amino acids in Xenopus Plk1 was shown to increase catalytic activity severalfold. Moreover, microinjection of Xenopus oocytes with the messenger RNA (mRNA) encoding this double point mutant led to direct activation of Cdc25C and Cyclin BCdk1 [79]. Along with additional biochemical evidence, these data were taken as support to the concept that Plk1 is the trigger of Cdc25C activation [79]. Studies conducted on HeLa cells reached slightly different conclusions on the importance of the two sites of phosphorylation in Plk1, in that they demonstrated that the key activating event is phosphorylation of the T-loop residue, and this correlates with entry into mitosis. The authors suggested that phosphorylation at the second site is likely limited to other stages of the cell cycle [80]. The kinase responsible for Plk1 phosphorylation at the Tloop residue was initially suggested to be Xenopus Plkk1 [81], which is the homologue of human Slk. However, recent reassessment of this issue led to the conclusion that rather than being an upstream activating kinase, Plkk1 may be a target of Plk1 at the G2/M transition [82], thus leaving the issue of the mechanism of Plk1 activation still open. The close similarity of the amino acid sequence around the Plk1 T-loop site to the consensus for PDK1 led others to speculate that the latter may be a Plk1-kinase [83], though in vivo and/or in vitro evidence to support this hypothesis is not available. The identity of the kinase responsible for in vivo phosphorylation of the second site described in the literature $\left(\mathrm{S}_{137}\right.$ in human Plk1) is as yet unknown.

Table 1. Protein kinases controlling the onset and progression through mitosis.

\begin{tabular}{|c|c|c|}
\hline $\begin{array}{l}\text { Protein } \\
\text { kinase }\end{array}$ & Function & References \\
\hline Cdk1 & $\begin{array}{l}\text { nuclear membrane breakdown, mitotic } \\
\text { spindle assembly, chromosome conden- } \\
\text { sation, APC/C regulation }\end{array}$ & $27-33 ; 44-61$ \\
\hline Plk1 & $\begin{array}{l}\text { centrosome maturation, microtubules } \\
\text { dynamics, chromosome segregation, } \\
\text { APC/C regulation, DNA damage recov- } \\
\text { ery }\end{array}$ & $79-92$ \\
\hline Nek2 & centrosome splitting & $102-105$ \\
\hline AurA & $\begin{array}{l}\text { centrosome separation, Cdk1/Cyclin B1 } \\
\text { activation }\end{array}$ & 110,116 \\
\hline AurB & $\begin{array}{l}\text { chromosomes condensation, chromo- } \\
\text { somes bi-orientation, cytokinesis }\end{array}$ & $128,144-150$ \\
\hline Mps1 & $\begin{array}{l}\text { centrosome duplication and separation, } \\
\text { chromatide-spindle attachment }\end{array}$ & 192 \\
\hline PKA & $\mathrm{APC} / \mathrm{C}$ regulation & 154 \\
\hline $\mathrm{PKC}$ & mitotic progression & 157 \\
\hline PI3K & cyclin B1 expression & 163 \\
\hline $\mathrm{Akt} / \mathrm{PKB}$ & G2/M checkpoint bypass & 161,165 \\
\hline
\end{tabular}


Cdc5p and Plk1 localize at centrosomes in early mitosis, redistribute to the spindle and mitotic bridge at anaphase [77] and are rapidly degraded by the APC/C-Cdh1 during exit from mitosis $[76,84,85]$. Whereas the Cdc5p degradation motif is localized at the N-terminus, Plk1 destruction depends on a D-box that is located in the central part of the protein [86]. The many functions of Plk1 at mitosis [87] are well accounted for by the variety of substrates so far identified for this kinase. These consist of proteins involved with chromosome segregation, such as cohesin [88], microtubules dynamics [89] and nucleation [90] as well as cytokinesis [91]. In addition to the regulation of mechanistic aspects of mitosis, Plk1 contributes to set the timing of entry and transition through mitosis by phosphorylating APC/C subunits [92, 93]. Another interesting control mechanism in which members of the Polo kinase family are involved is the control of mitosis in response to DNA damage (Fig. 2). When DNA damage occurs after replication (i.e., in G2), cells normally remain arrested for a limited period of time, after which they display 'adaptation' to damage. This response, which was initially observed in yeast and more recently described in Xenopus [94], consists in increased tolerance to DNA damage and results in the progression into the next phase of the cell cycle (i.e., G1) where repair is attempted [95]. Contrary to adaptation, 'recovery', which follows the successful repair of damage, is accompanied by downregulation of DNA damage response pathways and resumption of cell cycle progression. An S. cerevisiae CDC5 mutant was found to be adaptation-defective, and cells of this strain remained permanently arrested with large buds when irreparable DSB occurred in the genome [96]. This evidence prompted the search for a parallel response in human cells. Inhibition of Plk1 activity was indeed observed upon induction of DNA damage in G2 [97] or in M-phase [98]. Whereas in the first setting Plk1 inhibition was reported to be ATM- or ATR-dependent [99], DNA damage caused in M-phase led to Plk1 inhibition through dephosphorylation, and this effect was ATM-independent [98]. Considering that Plk1 does not contain consensus sequences for phosphorylation by ATM or ATR, it can be ruled out that Plk1 may serve as direct substrate for these DNA damage sensors (Fig. 2). On the other hand, the presence of potential phosphorylation sites for Chk1 or Chk2 suggests that Plk1 may be targeted by checkpoint kinases [100], an issue that has not been explored to date. In line with the evidence obtained in yeast, subsequent studies addressed the role of Plk1 during recovery from DNA damage [101]. Since the mechanism of recovery from DNA damage is still not fully understood in its molecular details, in the study conducted on human cells [101] recovery was mimicked by interrupting the flow of DNA damage signals with the ATM/ATR inhibitor caffeine. In this setting, Plk1 was shown to facilitate resumption of cell cycle progression and mitotic entry. At the molecular level, this occurred through phosphorylation-dependent degradation of Wee1 (Fig. 2), which together with Myt1 [102] is a known Plk1 substrate [103]. However, as for the report on Plk1 inhibition by DNA damage, both the pathway and the molecular mechanism supporting reactivation of DNA damageinhibited Plk1 during recovery remain to be clarified (see also below).

\section{Nek2}

Nek2 is a mammalian serine/threonine protein kinase displaying high sequence homology to NIMA, a kinase necessary for entry into mitosis in the filamentous fungus $\mathrm{As}$ pergillus nidulans [104]. Nek2 is a $48-\mathrm{kDa}$ protein comprising 445 residues with a catalytic domain localized at the $\mathrm{N}$-terminus of the molecule and a regulatory domain at the $\mathrm{C}$-terminus. Two regions predicted to fold as coiledcoils, with one of them displaying similarity to Leu-zippers, are present within the regulatory domain [105].

The mechanism of Nek2 activation has been only partially explored. It appears that homodimerization through the unusual Leu-zipper coiled-coil motif facilitates autophosphorylation in trans, and this results in enzymatic activation [106]. Autophosphorylation, though, may not be the only mode of kinase activation. A study investigating meiotic progression in mouse spermatocytes showed that the MAPK $/ \mathrm{p} 90^{\mathrm{Rsk} 2}$ pathway was required to control Nek2 activation and that the latter was an in vitro substrate for $\mathrm{p} 90^{\mathrm{Rsk} 2}$ [107]. The reported stoichiometric interaction of Nek2 with protein phosphatase 1 [108] may add a further layer of complexity to the regulation of Nek2 kinase activity, as was observed in the case of AurA (see below). Nek2 protein level is low in G1 and increases throughout S and G2 [109]. The protein is rapidly degraded at the pro-metaphase to metaphase transition of mitosis in an APC/C-Cdc20-dependent manner and with kinetics similar to Cyclin A [110]. Nek2 is a centrosomal resident protein that upon overexpression causes centrosome splitting [111], an event that is different from the physiological separation of centrosomes occurring at $\mathrm{G} 2 / \mathrm{M}$. In the case of centrosome splitting induced by overexpressed Nek2, mother and daughter centrioles appear to be separated by $>2 \mu \mathrm{m}$, though this is not followed by recruitment of motor proteins at centrosomes and assembly of a functional mitotic spindle [112]. Nek2-driven centrosome splitting is likely accomplished through phosphorylation of C-Nap1, a protein interacting with Nek2 and associated with the proximal ends of mother and daughter centrioles [113, 114].

The possible inhibition of Nek2 as contribution to the cell cycle arrest that follows damage to DNA has been addressed by a single study. The authors claimed that both 
kinase activity and Nek2 protein level were reduced upon DNA damage [115]. However, a note of caution should be added here, since rapid reduction of the transcription rate of genes encoding mitotic regulators is a known consequence of DNA damage [116] and may not be a specific Nek2 response.

\section{The Aurora kinases}

The Aurora kinases belong to a family of mitotic protein kinases that regulate centrosomal and microtubule activity, thus controlling the accuracy of chromosome segregation and cytokinesis [117]. Aurora proteins were first described in S. cerevisiae and Drosophila. One single form of the kinase, Ipl1, is expressed in yeast [118], whereas two members of the family are present in Drosophila (Aurora and IAL) [119] and at least three in mammals (Aurora A-C) [60]. Budding yeast Ipl1 mutants display abnormal ploidy [120]. Drosophila Aurora mutants typically display monopolar spindles as a result of defective centrosome separation [119]. Of the three human homologues so far described [117], AurA and AurB were isolated by means of degenerate oligo-based PCR [121], and in a screening for kinases overexpressed in colon carcinoma [122]. AurA is a nuclear protein that re-localizes to the centrosomes in late S and G2 and to the spindle throughout mitosis $[123,124]$. Depletion of AurA by small interfering RNA (siRNA) in HeLa cells results in an almost complete block of entry into mitosis [125], whereas overexpression of AurA causes transformation of Rat1 and NIH3T3 cells, which in turn can grow as tumors in nude mice [122]. Studies of the potential role of AurA in carcinogenesis have described the frequent amplification of AurA gene in human tumors and cancer cell lines as well as the high expression of AurA mRNA in a manner independent of gene amplification $[122,126,127]$.

The three mammalian Aurora members display a conserved catalytic core, which is flanked by $\mathrm{N}$ - and C-terminal domains containing regulatory motifs [128]. Among these is an N-terminal K-E-N motif, which is commonly the site of ubiquitinylation of APC/C-Cdh1 target proteins that are degraded at mitotic exit and early G1 [67]. However, deletion [129] or point mutation analysis [130] showed that the K-E-N motif is not required for AurA destruction. A silent C-terminal destruction box (D-box), similar to that found in cyclin B, is present in all members of the family. Contrary to AurB and AurC, however, AurA D-box is rendered functional by the presence of an N-terminal A-box (also known as D-box Activating Domain, DAD) [130, 131]. The A-box of Xenopus AurA encompasses a site, $\mathrm{Ser}_{53}$, the phosphorylation of which results in stabilization of the kinase $[130,132]$.
The mechanism of enzymatic activation has been addressed in detail for AurA. AurA activation requires phosphorylation at a number of sites [132], among which the T-loop residue ( $\mathrm{T}_{288}$ in human AurA) seems to be a key determinant. PKA was initially claimed to be responsible for phosphorylation at $T_{288}$ [133]. However, a recent reassessment of this issue where inhibitors and physiological activators of the cyclic AMP (cAMP)-dependent kinase were employed, ruled out the latter as upstream AurA-kinase [134]. In addition, the fact that the cAMP level, and consequently protein kinase A activity, decrease as cells approach mitosis [135] (see also below), leaves groundless any argument in favor of PKA. The evidence so far indicates that phosphorylation at $\mathrm{T}_{288}$ is the result of an autocatalytic event likely driven by clustering of AurA molecules [134, 136]. Arguments in favor of this hypothesis derive from studies on recombinant AurA as well as from in vitro reconstitution experiments. In bacteria, which notably contain no serine/threonine protein kinases, expression of Xenopus [136] or human [134, 137] recombinant AurA yields a kinase that is phosphorylated at multiple sites [134, 136], likely through an autocatalytic process, and is highly active. On the other hand, the lower degree of activity displayed by recombinant Xenopus AurA expressed in insect cells [132], and the fact that such activity can be boosted by treating cells with okadaic acid [132], indicates that in eukaryotic systems additional factors contribute to the control of AurA activity, as exemplified by the functional interaction with protein phosphatase 1 (see below). Xenopus AurA expressed in bacteria displayed stoichiometric phosphorylation at $\mathrm{T}_{295}$ [136], the T-loop site equivalent to $\mathrm{T}_{288}$ in human AurA. A recent study on human recombinant AurA provided the rationale for this observation. The authors showed that $\mathrm{T}_{288}$ is the only site in the kinase flanked by a sequence perfectly fitting the consensus for substrate phosphorylation by AurA [134]. In addition to autophosphorylation as a possible mechanism for AurA activation, in a recent report it was demonstrated that the small GTPase-activated kinase Pak1 is able to efficiently bind to inactive AurA and phosphorylate two of the three mitotic sites described in AurA, namely the T-loop $\mathrm{T}_{288}$ and the more downstream site $S_{342}$ [138]. Although the Authors were unable to show that known kinases present at centrosomes could activate Pak1, leaving thus open the search for upstream regulators of the cascade impinging on AurA, this study represents an important step in the reconstruction of the pathway upstream of AurA. Biochemical studies attempting in vitro reconstitution of the AurA activation system using Xenopus eggs extracts identified the motor-binding protein TPX2 (Targeting Protein for Xenopus kinesin-like protein-2) as an in vitro activator of AurA [139]. TPX2, which is normally localized to the nucleus through active shuttling by Importin- $\beta$, is released in a Ran-GTP-dependent manner as cells approach mito- 
sis and drives localization of AurA at centrosomes [140]. This would be consistent with observations made in vitro, in that close proximity of AurA molecules facilitates autophosphorylation and kinase activation. Structural studies where AurA and TPX2 were co-crystallized, confirmed the key role played by TPX2 in maintaining the phosphorylated $\mathrm{T}_{288}$ residue in a buried position where it is protected from dephosphorylation, thus locking AurA in an active conformation [141].

The catalytic domain of AurA contains two R/K-V-X-F motifs that have been implicated in binding protein phosphatase 1 (PP1) in a functional manner [142]. Although the mechanism of mutual control of PP1 and AurA has not been dissected at the molecular level, as postulated for the Nek2-PP1 interaction [108], the activating reactions of AurA autophosphorylation and PP1 autodephosphorylation compete with the opposite (inhibitory) reactions resulting in reciprocal regulation of enzymatic activity [142]. However, how the balance of these competing reactions is tilted to one or the other side during progression to mitosis is still unclear. The observation that treatment of cells with the PP1 inhibitor okadaic acid leads to hyperactivation of AurA [132], likely by preventing $\mathrm{T}_{288}$ dephosphorylation, supports the idea of an inhibitory role for PP1. This simple interpretation, however, is invalidated by evidence that AurA mutants unable to bind PP1 are enzymatically inactive [142]. Therefore, it appears that in addition to phosphatase activity, PP1 binding per se has a role in controlling AurA activity. Another twist to the story was brought by the evidence that the PP1 inhibitor-2 protein (I-2) behaves as allosteric activator of AurA in vitro, in a manner similar but not additive to TPX2 [143]. In this study it was demonstrated that the effect of I-2 on AurA was independent of inhibition of PP1 activity. Among other proteins interacting with AurA is AIP, which affects AurA protein level through proteasome-dependent degradation [144], and the LIM-protein Ajuba, which behaves like an AurA allosteric activator [125]. TPX2 and Ajuba are phosphorylated by AurA, and the list of current AurA substrates includes the kinesinlike protein Eg5 [117], the Cdc25B phosphatase [145], BRCA1 [146] and p53 [147].

As for CDK1 and Plk1, the activity of AurA is also inhibited in response to genotoxic damage [124, 148]. The pathway relaying DNA damage signals to AurA depends on CHK1 and results in phosphorylation of AurA at the inhibitory site $S_{342}$ [124] (Fig. 2). An interesting issue is whether mitotic kinases are inhibited by DNA damage signals in parallel or in series. Addressing this question requires a careful experimental setting allowing coordinated introduction of an active form of the kinase under investigation in DNA damaged cells and monitoring of progression through mitosis. To this end, transient or stable expression of a kinase is not a suitable approach, given two major drawbacks: (i) the excessive production of recombinant protein in the case of continuous expression and (ii) the slow kinetic of protein expression in the case of inducible constructs, which is incompatible with the rapid sequence of events at mitosis. The correct experimental setting was identified in a recent study on AurA where physiological amounts of purified and highly active AurA protein were transduced in DNA damaged cells precisely after induction of damage in G2synchronized cells [124]. The authors could show that this approach resulted in bypass of the G2 DNA damage checkpoint and progression to mitosis, and this was characterized by reactivation of DNA damage-inhibited Cdk1. Considering that Cdk1 is not a substrate for AurA, it must be inferred that AurA controls Cdk1 through the upstream regulators Cdc25B or Wee1/Myt1 [124] (Fig. 2).

As for AurA, the AurB protein level is cell cycle regulated. AurB kinase activity peaks after AurA and following the inactivation of Cdk1 [122], though this is not linked to the triggering of AurB activity. AurB is a chromosomal passenger protein which relocalizes at the midzone of anaphase cells and at the post-mitotic bridge of telophase cells $[128,149]$. AurB is activated by autophosphorylation at the T-loop residue $\mathrm{T}_{232}$ [150] upon interaction with the inner centromere protein INCENP [151] [152]. Ectopic expression of kinase inactive AurB results in the appearance of multinucleated cells, a phenotype that has been attributed to a defect in the final step of cytokinesis [153]. RNA interference studies on Drosophila AurB confirmed the occurrence of chromosome condensation and segregation defects followed by failure at cytokinesis [154]. Such a variety of effects may find a ground in the multiplicity of pathways affected by AurB. AurB has been described as a kinase capable of phosphorylating $\mathrm{Ser}_{10}$ and $\mathrm{Ser}_{28}$ in histone $\mathrm{H} 3[137,154$ 156]. Ser ${ }_{10}$ phosphorylation starts at the pericentromeric region in G2, spreads through the entire length of chromosomes by metaphase [157] and is required for initiation, but not maintenance, of mammalian chromosome condensation [158]. Although Histone H3 phosphorylation by AurB is not sufficient per se to trigger chromosome condensation, it was recently demonstrated to be a dynamic way to mark chromatin that results in the release of HP1 at M phase [159, 160]. HP1 is a protein that associates to $\mathrm{H} 3$ in interphase through methylated $\mathrm{Lys}_{9}$ and plays a role in the architecture of chromatin. The role of AurB-dependent $\mathrm{H} 3$ phosphorylation is underscored by the fact that vertebrate cells functionally deficient in AurB fail in condensing chromosomes, in addition to displaying defective alignment and segregation of chromosomes $[161,162]$. Moreover, defective AurB-dependent phosphorylation of MCAK (mitotic centromere-asssociated kinesin) [163-165] may relate to the inability of correcting improper kinetochore attachment during chromosome bi-orientation (see above). Finally, lack of phospho- 
rylation of another AurB substrate, the filament protein vimentin [166] that is involved in shaping the cleavage furrow at cytokinesis, results in cytokinesis failure.

\section{Other protein kinases affecting the onset of mitosis}

A number of studies have pointed to a role for other protein kinases in the control of mitosis, though only in some cases the analysis was sufficiently complete to allow a final statement of their importance. It is, nevertheless, worth mentioning these data, as they may prompt novel studies reassessing and eventually expanding the initial findings. Most of the kinases listed below were initially identified and characterized in a cell cycle-independent context, and only later was their involvement in cell cycle transitions examined.

Early studies on HeLa cells showed that the concentration of the second messenger and PKA activator cAMP is low at mitosis and high in late G1 and early S-phase [167]. Moreover, it was reported that artificial elevation of cAMP levels in S or G2 caused G2 arrest and lengthening of M-phase. In contrast, addition of cAMP analogues at metaphase had the opposite effect, resulting in an accelerated exit from mitosis [167]. Similar data were obtained in yeast [168]. Analysis of Xenopus eggs confirmed that the minimum level of cAMP was observed at the onset of mitosis and this was followed by an increase in the cyclic nucleotide at the mitosis-interphase transition [169]. Moreover, blocking the activation of PKA at metaphase was shown to prevent transition through mitosis [135]. Light was shed in part on the molecular mechanism underlying these effects by the finding that PKA is responsible for phosphorylation and inhibition of components of the $20 \mathrm{~S}$ complex at the onset of mitosis [170]. The 20S complex, also known as $\mathrm{APC} / \mathrm{C}$, is required for the destruction of mitotic cyclins and for the separation of sister chromatids at the anaphase-to-metaphase transition [67]. The correct timing of $\mathrm{APC} / \mathrm{C}$ activation at metaphase is apparently controlled by positive phosphorylation resulting from the increasing activity of Plk1 and by protein phosphatase 1 (PP1)-mediated [171] dephosphorylation of inhibitory sites that are targets of PKA [92].

Here, however, the reader should bear in mind that not all effects of cAMP are mediated through the activation of PKA [172]. Furthermore, considering that the consensus sequence for substrate phosphorylation by PKA significantly overlaps with that of many basophilic protein kinases [173], genuine PKA substrates should only be declared such upon converging in vitro and in vivo evidence, possibly accompanied by genetic scrutiny of the pathway in which PKA is hypothesized to play a role.

The yeast calcium and phospholipid-dependent protein kinase (PKC1) was shown to be required for progression to mitosis, with deletion mutants displaying a G2 arrest characteristic of cell division cycle mutants [174]. Studies on mammalian cells confirmed these results, showing an increase in the nuclear level of the PKC activator diacyclglycerol at G2/M [175], an event that would facilitate triggering of PKC-mediated phosphorylation of proteins involved with mitosis such as vimentin [176], lamin A [177] or lamin B [175].

Perhaps one of the most interesting kinase cascades shown to play a role at the G2/M transition is the phosphoinositide 3 kinase (PI3K)/3'-phosphoinositide-dependent kinase 1 (PDK1)/protein kinase B (Akt/PKB) pathway. Studies on MDCK cells showed that Akt/PKB activity is high at $\mathrm{G} 2 / \mathrm{M}$ and that the cell cycle block imposed by inhibitors of PI3K could be bypassed by expression of constitutive active Akt/PKB mutants [178]. Other studies based on the use of cell-permeable inhibitors and dominant-negative mutants concluded that the PI3K pathway is activated prior to completion of DNA synthesis [179] and contributes to cyclin B1 expression and Cdk1 activation [180]. Accordingly, expression of a constitutively active form of PI3K was reported to delay mitotic exit due to defective cytokinesis, and these effects were attributed to altered phosphorylation of the Akt/PKB substrates forkhead-transcription factors [181]. An intriguing function of Akt/PKB is its role in mediating bypass of the G2/ $M$ checkpoint activated in response to genotoxic damage [182], which stems, at least in part, from the ability of Akt/PKB to mitigate DNA damage-dependent inhibition of Cdk1 [182]. The molecular mechanism underlying resistance of Cdk1 to inhibition by genotoxic agents in cells expressing activated $\mathrm{Akt} / \mathrm{PKB}$ is not known, though evidence that Akt/PKB-dependent phosphorylation of Chk1 at $S_{280}$ renders the latter apparently refractive to activation by ATM/ATR may provide an answer [183]. Considering that phosphorylation-dependent inhibition of the E3 ligase responsible for Plk1 degradation is controlled by Akt/ PKB and results in stabilization and reactivation of Plk1 [184], and this is eventually necessary to recover from DNA damage [101], this could represent another level at which Akt/PKB participates in reinforcing the loop controlling Cdk1 activity [185]. Indirect support to this comes from a study where depletion of Pdk1p (the Schizosaccharomyces pombe homologue of human PDK1, an activating kinase upstream of $\mathrm{Akt} / \mathrm{PKB}$ ) resulted in defects in mitosis and cytokinesis that were exacerbated by compromising the function of Plolp, the fission yeast polo kinase $1[186]$.

\section{Conclusions}

Mitosis is an extraordinarily regulated process that results in the segregation of sister chromatids into two newly made cells. Early biochemical studies on cell division have led to the identification of Cdk1 as the histone $\mathrm{H} 1$ 
kinase with the highest specific activity in mitotic cells. The evidence acquired since the discovery of Cdk1 has exposed many of the pathways controlled by this kinase, and this has earned Cdk1 the designation of 'master mitotic regulator'. Although Cdk1 remains the undisputed central controller of mitosis, recent investigations have expanded our understanding of cell division by revealing the presence of ancillary activities, such as those of Plk1, NIMA and Aurora-related protein kinases, which are crucial in setting the stage, lead to commitment to and facilitate the execution of mitosis. The discovery of crosstalk between mitotic kinases, as is the case for the Aurora A-dependent Cdk1 recruitment and activation at the centrosome in G2 [125] or the regulation of Cdk1/Cyclin B1 nuclear localization by Plk1 at prophase [187], has shown that further layers of control contribute to increase the complexity of mitotic onset. Finally, the effect of 'noncanonical' mitotic kinases in setting the stage for mitosis through indirect control of Cdk1, the best example being illustrated by the PI3K-Akt/PKB pathway, indicates that reconsidering with an open mind kinase cascades that have established roles in other phases of the cell cycle will likely provide interesting surprises.

Clearly, what is sketched in this essay is only one side of the coin, and the final picture of mitotic control will have to take into account the opposite contribution of phosphorylation and dephosphorylation.

\section{Perspectives}

The evidence acquired to date on the role of phosphorylation should be sufficient to equate it to the relevance of gravitation in physics and, thus, counter the skepticism of those who did not initially acknowledge the importance of phosphorylation in biology. It is expected that future research will take advantage of large-scale proteomic analysis to expose the full repertoire of post-translational modifications of mitotic protein kinases in specific, and of proteins in general. This, in turn, will provide hints of how the information stored in the relatively small pool of genes present in our genome can give rise to the complexity of the metabolic pathways that scientists are dissecting. Thus, after having cracked the DNA code, the challenge ahead lies in the detailed exposure of mechanisms and modalities of regulation of the proteome, which will give us tools to understand the intricacy of metabolic networks [188] and the robustness of complex systems [189].

Acknowledgments. I would like to thank L. A. Pinna, M. El-Shemerly and A. Krystyniak for critical reading of the manuscript and useful suggestions. My apologies to those colleagues whose work has not been cited due to space constraints. This work was supported by a grant of the Cancer League Zurich. The data shown in Figure 1B were obtained at RSCB PBD (http://www.rcsb.org/pdb/) [190] and visualized using iMol V. 0.1 for the Macintosh.
1 Burnett G. and Kennedy E. P. (1954) The enzymatic phosphorylation of proteins. J. Biol. Chem. 211: 969-980

2 Fischer E. H. and Krebs E. G. (1955) Conversion of phosphorylase $\mathrm{b}$ to phosphorylase a in muscle extracts. J. Biol. Chem. 216: $121-132$

3 Sutherland E. W. Jr and Wosilait W. D. (1955) Inactivation and activation of liver phosphorylase. Nature 175: 169-170

4 Krebs E. G., Graves D. J. and Fischer E. H. (1959) Factors affecting the activity of muscle phosphorylase $b$ kinase. J. Biol. Chem. 234: 2867-2873

5 Chan G. K. and Yen T. J. (2003) The mitotic checkpoint: a signaling pathway that allows a single unattached kinetochore to inhibit mitotic exit. Prog. Cell Cycle Res. 5: 431-439

6 Musacchio A. and Hardwick K. G. (2002) The spindle checkpoint: structural insights into dynamic signalling. Nat. Rev. Mol. Cell. Biol. 3: 731-741

7 Vanoosthuyse V. and Hardwick K. G. (2005) Bub1 and the multilayered inhibition of $\mathrm{Cdc} 20-\mathrm{APC} / \mathrm{C}$ in mitosis. Trends Cell Biol. 15: 231-233

8 Hanks S. K., Quinn A. M. and Hunter T. (1988) The protein kinase family: conserved features and deduced phylogeny of the catalytic domains. Science 241: 42-52

9 Hunter T. (1987) A thousand and one protein kinases. Cell 50: 823-829

10 Hanks S. K. (2003) Genomic analysis of the eukaryotic protein kinase superfamily: a perspective. Genome Biol. 4: 111

11 Manning G., Whyte D. B., Martinez R., Hunter T. and Sudarsanam S. (2002) The protein kinase complement of the human genome. Science 298: 1912-1934

12 Manning G., Plowman G. D., Hunter T. and Sudarsanam S. (2002) Evolution of protein kinase signaling from yeast to man. Trends Biochem. Sci. 27: 514-520

13 Johnson L. N. and Lewis R. J. (2001) Structural basis for control by phosphorylation. Chem. Rev. 101: 2209-2242

14 Huse M. and Kuriyan J. (2002) The conformational plasticity of protein kinases. Cell 109: 275-282

15 Johnson L. N., Noble M. E. and Owen D. J. (1996) Active and inactive protein kinases: structural basis for regulation. Cell 85: $149-158$

16 Nolen B., Taylor S. and Ghosh G. (2004) Regulation of protein kinases; controlling activity through activation segment conformation. Mol. Cell 15: 661-675

17 Wolf I., Rubinfeld H., Yoon S., Marmor G., Hanoch T. and Seger R. (2001) Involvement of the activation loop of ERK in the detachment from cytosolic anchoring. J. Biol. Chem. 276: 24490-24497

18 Mazzarello P. (1999) A unifying concept: the history of cell theory. Nat. Cell Biol. 1: E13-E15

19 Boveri T. (1910) Ueber die Teilung centrigugierte Eier von Ascaris megalocephala. Wilhelm Roux Arch. Entwicklungsmech. Org. 30: 101-125

20 Kwon M. and Scholey J. M. (2004) Spindle mechanics and dynamics during mitosis in Drosophila. Trends Cell Biol. 14: 194-205

21 Watrin E. and Legagneux V. (2003) Introduction to chromosome dynamics in mitosis. Biol. Cell 95: 507-513

22 Swedlow J. R. and Hirano T. (2003) The making of the mitotic chromosome: modern insights into classical questions. Mol. Cell 11: 557-569

23 Castro A., Bernis C., Vigneron S., Labbe J. C. and Lorca T. (2005) The anaphase-promoting complex: a key factor in the regulation of cell cycle. Oncogene 24: 314-325

24 Pines J. and Rieder C. L. (2001) Re-staging mitosis: a contemporary view of mitotic progression. Nat. Cell Biol. 3: E3-E6

25 Nurse P. (1975) Genetic control of cell size at cell division in yeast. Nature 256: $547-551$

26 Masui Y. and Markert C. L. (1971) Cytoplasmic control of nuclear behavior during meiotic maturation of frog oocytes. J. Exp. Zool. 177: 129-145 
27 Smith L. D. and Ecker R. E. (1971) The interaction of steroids with Rana pipiens Oocytes in the induction of maturation. Dev. Biol. 25: 232-247

28 Lohka M. J., Hayes M. K. and Maller J. L. (1988) Purification of maturation-promoting factor, an intracellular regulator of early mitotic events. Proc. Natl. Acad. Sci. USA 85: 3009 3013

29 Gautier J., Norbury C., Lohka M., Nurse P. and Maller J. (1988) Purified maturation-promoting factor contains the product of a Xenopus homolog of the fission yeast cell cycle control gene cdc2+. Cell 54: 433-439

30 Arion D., Meijer L., Brizuela L. and Beach D. (1988) cdc2 is a component of the M phase-specific histone H1 kinase: evidence for identity with MPF. Cell 55: 371-378

31 Dunphy W. G., Brizuela L., Beach D. and Newport J. (1988) The Xenopus cdc2 protein is a component of MPF, a cytoplasmic regulator of mitosis. Cell 54: 423-431

32 Labbe J. C., Lee M. G., Nurse P., Picard A. and Doree M. (1988) Activation at M-phase of a protein kinase encoded by a starfish homologue of the cell cycle control gene cdc2+. Nature 335: 251-254

33 Gautier J., Minshull J., Lohka M., Glotzer M., Hunt T. and Maller J. L. (1990) Cyclin is a component of maturation-promoting factor from Xenopus. Cell 60: 487-494

34 Labbe J. C., Capony J. P., Caput D., Cavadore J. C., Derancourt J., Kaghad M. et al. (1989) MPF from starfish oocytes at first meiotic metaphase is a heterodimer containing one molecule of cdc2 and one molecule of cyclin B. EMBO J. 8: 3053-3058

35 Morgan D. O. (1995) Principles of CDK regulation. Nature 374: $131-134$

36 Zwicker J., Lucibello F. C., Wolfraim L. A., Gross C., Truss M., Engeland K. et al. (1995) Cell cycle regulation of the cyclin $\mathrm{A}$, cdc $25 \mathrm{C}$ and cdc2 genes is based on a common mechanism of transcriptional repression. EMBO J. 14: 4514-4522

37 Hwang A., McKenna W. G. and Muschel R. J. (1998) Cell cycle-dependent usage of transcriptional start sites. A novel mechanism for regulation of cyclin B1. J. Biol. Chem. 273: 31505-31509

38 Jeffrey P. D., Russo A. A., Polyak K., Gibbs E., Hurwitz J., Massague J. et al. (1995) Mechanism of CDK activation revealed by the structure of a cyclinA-CDK2 complex. Nature 376: $313-320$

39 Devault A., Martinez A. M., Fesquet D., Labbe J. C., Morin N., Tassan J. P. et al. (1995) MAT1 ('menage a trois') a new RING finger protein subunit stabilizing cyclin $\mathrm{H}$-cdk7 complexes in starfish and Xenopus CAK. EMBO J. 14: 5027-5036

40 Tassan J. P., Jaquenoud M., Fry A. M., Frutiger S., Hughes G. J. and Nigg E. A. (1995) in vitro assembly of a functional human CDK7-cyclin H complex requires MAT1, a novel $36 \mathrm{kDa}$ RING finger protein. EMBO J. 14: 5608-5617

41 Gu Y., Rosenblatt J. and Morgan D. O. (1992) Cell cycle regulation of CDK2 activity by phosphorylation of Thr160 and Tyr15. EMBO J. 11: 3995-4005

42 Ohta T., Okamoto K., Isohashi F., Shibata K., Fukuda M., Yamaguchi S. et al. (1998) T-loop deletion of CDC2 from breast cancer tissues eliminates binding to cyclin B1 and cyclin-dependent kinase inhibitor p21. Cancer Res. 58: 1095-1098

43 Gould K. L. and Nurse P. (1989) Tyrosine phosphorylation of the fission yeast cdc $2+$ protein kinase regulates entry into mitosis. Nature 342: 39-45

44 Atherton-Fessler S., Parker L. L., Geahlen R. L. and PiwnicaWorms H. (1993) Mechanisms of p34cdc2 regulation. Mol. Cell. Biol. 13: 1675-1685

45 Izumi T. and Maller J. L. (1993) Elimination of cdc2 phosphorylation sites in the cdc25 phosphatase blocks initiation of M-phase. Mol. Biol. Cell 4: 1337-1350

46 Strausfeld U., Fernandez A., Capony J. P., Girard F., Lautredou N., Derancourt J. et al. (1994) Activation of $\mathrm{p} 34 \mathrm{cdc} 2$ protein kinase by microinjection of human cdc $25 \mathrm{C}$ into mammalian cells. Requirement for prior phosphorylation of $\operatorname{cdc} 25 \mathrm{C}$ by p34cdc2 on sites phosphorylated at mitosis. J. Biol. Chem. 269: $5989-6000$

47 Toyoshima-Morimoto F., Taniguchi E. and Nishida E. (2002) Plk1 promotes nuclear translocation of human $\mathrm{Cdc} 25 \mathrm{C}$ during prophase. EMBO Rep. 3: 341-348

48 De Bondt H. L., Rosenblatt J., Jancarik J., Jones H. D., Morgan D. O. and Kim S. H. (1993) Crystal structure of cyclin-dependent kinase 2. Nature 363: 595-602

49 Booher R. and Beach D. (1987) Interaction between cdc13+ and cdc2+ in the control of mitosis in fission yeast: dissociation of the $\mathrm{G} 1$ and $\mathrm{G} 2$ roles of the cdc2+ protein kinase. EMBO J. 6: $3441-3447$

50 Lee M. G. and Nurse P. (1987) Complementation used to clone a human homologue of the fission yeast cell cycle control gene cdc2. Nature 327: 31-35

51 Lehner C. F. and O'Farrell P. H. (1990) Drosophila cdc2 homologs: a functional homolog is coexpressed with a cognate variant. EMBO J. 9: 3573-3581

52 Fang F. and Newport J. W. (1991) Evidence that the G1-S and G2-M transitions are controlled by different cdc2 proteins in higher eukaryotes. Cell 66: 731-742

53 Ninomiya-Tsuji J., Nomoto S., Yasuda H., Reed S. I. and Matsumoto K. (1991) Cloning of a human cDNA encoding a CDC2-related kinase by complementation of a budding yeast cdc28 mutation. Proc. Natl. Acad. Sci. USA 88: 9006-9010

54 Riabowol K., Draetta G., Brizuela L., Vandre D. and Beach D. (1989) The cdc2 kinase is a nuclear protein that is essential for mitosis in mammalian cells. Cell 57: 393-401

55 Picard A., Labbe J. C., Barakat H., Cavadore J. C. and Doree M. (1991) Okadaic acid mimics a nuclear component required for cyclin B-cdc2 kinase microinjection to drive starfish oocytes into M phase. J. Cell Biol. 115: 337-344

56 van den Heuvel S. and Harlow E. (1993) Distinct roles for cyclin-dependent kinases in cell cycle control. Science 262: 2050-2054

57 Bunz F., Dutriaux A., Lengauer C., Waldman T., Zhou S., Brown J. P. et al. (1998) Requirement for p53 and p21 to sustain G2 arrest after DNA damage. Science 282: 1497-1501

58 Chen J., Jackson P. K., Kirschner M. W. and Dutta A. (1995) Separate domains of p21 involved in the inhibition of Cdk kinase and PCNA. Nature 374: 386-388

59 Knockaert M., Greengard P. and Meijer L. (2002) Pharmacological inhibitors of cyclin-dependent kinases. Trends Pharmacol. Sci. 23: 417-425

60 Nigg E. A. (2001) Mitotic kinases as regulators of cell division and its checkpoints. Nat. Rev. Mol. Cell. Biol. 2: 21-32

61 Peter M., Heitlinger E., Haner M., Aebi U. and Nigg E. A. (1991) Disassembly of in vitro formed lamin head-to-tail polymers by CDC2 kinase. EMBO J. 10: 1535-1544

62 Blangy A., Lane H. A., d'Herin P., Harper M., Kress M. and Nigg E. A. (1995) Phosphorylation by p34cdc2 regulates spindle association of human Eg5, a kinesin-related motor essential for bipolar spindle formation in vivo. Cell 83: 1159-1169

63 Kimura K., Hirano M., Kobayashi R. and Hirano T. (1998) Phosphorylation and activation of $13 \mathrm{~S}$ condensin by Cdc2 in vitro. Science 282: 487-490

64 Sudakin V., Ganoth D., Dahan A., Heller H., Hershko J., Luca F. C. et al. (1995) The cyclosome, a large complex containing cyclin-selective ubiquitin ligase activity, targets cyclins for destruction at the end of mitosis. Mol. Biol. Cell 6: 185-197

65 Patra D. and Dunphy W. G. (1998) Xe-p9, a Xenopus Suc1/ Cks protein, is essential for the Cdc2-dependent phosphorylation of the anaphase- promoting complex at mitosis. Genes Dev. 12: 2549-2559

66 Zachariae W., Schwab M., Nasmyth K. and Seufert W. (1998) Control of cyclin ubiquitination by CDK-regulated binding of Hct1 to the anaphase promoting complex. Science 282: 17211724 
67 Peters J. M. (2002) The anaphase-promoting complex: proteolysis in mitosis and beyond. Mol. Cell 9: 931-943

68 Sunkel C. E. and Glover D. M. (1988) polo, a mitotic mutant of Drosophila displaying abnormal spindle poles. J. Cell Sci. 89 (Pt 1): 25-38

69 Kitada K., Johnson A. L., Johnston L. H. and Sugino A. (1993) A multicopy suppressor gene of the Saccharomyces cerevisiae G1 cell cycle mutant gene dbf4 encodes a protein kinase and is identified as CDC5. Mol. Cell. Biol. 13: 4445-4457

70 Lowery D. M., Lim D. and Yaffe M. B. (2005) Structure and function of Polo-like kinases. Oncogene 24: 248-259

71 Elia A. E., Cantley L. C. and Yaffe M. B. (2003) Proteomic screen finds $\mathrm{pSer} / \mathrm{p}$ Thr-binding domain localizing Plk1 to mitotic substrates. Science 299: 1228-1231

72 Mundt K. E., Golsteyn R. M., Lane H. A. and Nigg E. A. (1997) On the regulation and function of human polo-like kinase 1 (PLK1): effects of overexpression on cell cycle progression. Biochem. Biophys. Res. Commun. 239: 377-385

73 Jang Y. J., Lin C. Y., Ma S. and Erikson R. L. (2002) Functional studies on the role of the C-terminal domain of mammalian polo-like kinase. Proc. Natl. Acad. Sci. USA 99: 1984-1989

74 Song S., Grenfell T. Z., Garfield S., Erikson R. L. and Lee K. S. (2000) Essential function of the polo box of Cdc5 in subcellular localization and induction of cytokinetic structures. Mol. Cell. Biol. 20: 286-298

75 Lee K. S., Grenfell T. Z., Yarm F. R. and Erikson R. L. (1998) Mutation of the polo-box disrupts localization and mitotic functions of the mammalian polo kinase Plk. Proc. Natl. Acad. Sci. USA 95: 9301-9306

76 Cheng L., Hunke L. and Hardy C. F. (1998) Cell cycle regulation of the Saccharomyces cerevisiae polo-like kinase cdc5p. Mol. Cell. Biol. 18: 7360-7370

77 Golsteyn R. M., Mundt K. E., Fry A. M. and Nigg E. A. (1995) Cell cycle regulation of the activity and subcellular localization of Plk1, a human protein kinase implicated in mitotic spindle function. J. Cell Biol. 129: 1617-1628

78 Lee K. S. and Erikson R. L. (1997) Plk is a functional homolog of Saccharomyces cerevisiae Cdc5, and elevated Plk activity induces multiple septation structures. Mol. Cell. Biol. 17: $3408-3417$

79 Qian Y. W., Erikson E. and Maller J. L. (1999) Mitotic effects of a constitutively active mutant of the Xenopus polo-like kinase Plx1. Mol. Cell. Biol. 19: 8625-8632

80 Jang Y. J., Ma S., Terada Y. and Erikson R. L. (2002) Phosphorylation of threonine 210 and the role of serine 137 in the regulation of mammalian polo-like kinase. J. Biol. Chem. 277: 44115-44120

81 Qian Y. W., Erikson E. and Maller J. L. (1998) Purification and cloning of a protein kinase that phosphorylates and activates the polo-like kinase Plx1. Science 282: 1701-1704

82 Erikson E., Haystead T. A., Qian Y. W. and Maller J. L. (2004) A feedback loop in the polo-like kinase activation pathway. J. Biol. Chem. 279: 32219-32224

83 Kelm O., Wind M., Lehmann W. D. and Nigg E. A. (2002) Cell cycle-regulated phosphorylation of the Xenopus polo-like kinase Plx1. J. Biol. Chem. 277: 25247-25256

84 Shirayama M., Zachariae W., Ciosk R. and Nasmyth K. (1998) The Polo-like kinase Cdc5p and the WD-repeat protein $\mathrm{Cdc} 20 \mathrm{p} /$ fizzy are regulators and substrates of the anaphase promoting complex in Saccharomyces cerevisiae. EMBO J. 17: $1336-1349$

85 Lindon C. and Pines J. (2004) Ordered proteolysis in anaphase inactivates $\mathrm{Plk} 1$ to contribute to proper mitotic exit in human cells. J. Cell Biol. 164: 233-241

86 Barr F. A., Sillje H. H. and Nigg E. A. (2004) Polo-like kinases and the orchestration of cell division. Nat. Rev. Mol. Cell. Biol. 5: 429-440

87 van Vugt M. A. and Medema R. H. (2005) Getting in and out of mitosis with Polo-like kinase-1. Oncogene 24: 2844-2859
88 Alexandru G., Uhlmann F., Mechtler K., Poupart M. A. and Nasmyth K. (2001) Phosphorylation of the cohesin subunit Scc1 by Polo/Cdc5 kinase regulates sister chromatid separation in yeast. Cell 105: 459-472

89 Yarm F. R. (2002) Plk phosphorylation regulates the microtubule-stabilizing protein TCTP. Mol. Cell. Biol. 22: 6209-6221

90 Casenghi M., Meraldi P., Weinhart U., Duncan P. I., Korner R. and Nigg E. A. (2003) Polo-like kinase 1 regulates Nlp, a centrosome protein involved in microtubule nucleation. Dev. Cell 5: $113-125$

91 Zhou T., Aumais J. P., Liu X., Yu-Lee L. Y. and Erikson R. L. (2003) A role for Plk1 phosphorylation of NudC in cytokinesis. Dev. Cell 5: 127-138

92 Kotani S., Tugendreich S., Fujii M., Jorgensen P. M., Watanabe N., Hoog C. et al. (1998) PKA and MPF-activated pololike kinase regulate anaphase-promoting complex activity and mitosis progression. Mol. Cell 1: 371-380

93 Kraft C., Herzog F., Gieffers C., Mechtler K., Hagting A., Pines J. et al. (2003) Mitotic regulation of the human anaphase-promoting complex by phosphorylation. EMBO J. 22: 6598-6609

94 Yoo H. Y., Kumagai A., Shevchenko A., Shevchenko A. and Dunphy W. G. (2004) Adaptation of a DNA replication checkpoint response depends upon inactivation of Claspin by the Polo-like kinase. Cell 117: 575-588

95 Andreassen P. R., Lohez O. D. and Margolis R. L. (2003) G2 and spindle assembly checkpoint adaptation, and tetraploidy arrest: implications for intrinsic and chemically induced genomic instability. Mutat. Res. 532: 245-253

96 Toczyski D. P., Galgoczy D. J. and Hartwell L. H. (1997) CDC5 and CKII control adaptation to the yeast DNA damage checkpoint. Cell 90: 1097-1106

97 Smits V. A., Klompmaker R., Arnaud L., Rijksen G., Nigg E. A. and Medema R. H. (2000) Polo-like kinase-1 is a target of the DNA damage checkpoint. Nat. Cell Biol. 2: 672-676

98 Yuan J. H., Feng Y., Fisher R. H., Maloid S., Longo D. L. and Ferris D. K. (2004) Polo-like kinase 1 inactivation following mitotic DNA damaging treatments is independent of ataxia telangiectasia mutated kinase. Mol. Cancer Res. 2: 417-426

99 van Vugt M. A., Smits V. A., Klompmaker R. and Medema R. H. (2001) Inhibition of Polo-like kinase-1 by DNA damage occurs in an ATM- or ATR-dependent fashion. J. Biol. Chem. 276: $41656-41660$

100 Seo G. J., Kim S. E., Lee Y. M., Lee J. W., Lee J. R., Hahn M. J. et al. (2003) Determination of substrate specificity and putative substrates of Chk2 kinase. Biochem. Biophys. Res. Commun. 304: 339-343

101 van Vugt M. A., Bras A. and Medema R. H. (2004) Polo-like kinase-1 controls recovery from a G2 DNA damage-induced arrest in mammalian cells. Mol. Cell 15: 799-811

102 Nakajima H., Toyoshima-Morimoto F., Taniguchi E. and Nishida E. (2003) Identification of a consensus motif for Plk (Polo-like kinase) phosphorylation reveals Myt1 as a Plk1 substrate. J. Biol. Chem. 278: 25277-25280

103 Watanabe N., Arai H., Nishihara Y., Taniguchi M., Watanabe N., Hunter T. et al. (2004) M-phase kinases induce phosphodependent ubiquitination of somatic Weel by SCFbeta-TrCP. Proc. Natl. Acad. Sci. USA 101: 4419-4424

104 Osmani S. A., Pu R. T. and Morris N. R. (1988) Mitotic induction and maintenance by overexpression of a G2-specific gene that encodes a potential protein kinase. Cell 53: 237-244

105 Fry A. M. (2002) The Nek2 protein kinase: a novel regulator of centrosome structure. Oncogene 21: 6184-6194

106 Fry A. M., Arnaud L. and Nigg E. A. (1999) Activity of the human centrosomal kinase, Nek2, depends on an unusual leucine zipper dimerization motif. J. Biol. Chem. 274: 16304 16310

107 Di Agostino S., Rossi P., Geremia R. and Sette C. (2002) The MAPK pathway triggers activation of Nek2 during chromo- 
some condensation in mouse spermatocytes. Development 129: $1715-1727$

108 Helps N. R., Luo X., Barker H. M. and Cohen P. T. (2000) NIMA-related kinase 2 (Nek2), a cell-cycle-regulated protein kinase localized to centrosomes, is complexed to protein phosphatase 1. Biochem. J. 349: 509-518

109 Fry A. M., Schultz S. J., Bartek J. and Nigg E. A. (1995) Substrate specificity and cell cycle regulation of the Nek2 protein kinase, a potential human homolog of the mitotic regulator NIMA of Aspergillus nidulans. J. Biol. Chem. 270: 1289912905

110 Hames R. S., Wattam S. L., Yamano H., Bacchieri R. and Fry A. M. (2001) APC/C-mediated destruction of the centrosomal kinase Nek2A occurs in early mitosis and depends upon a cyclin A-type D-box. EMBO J. 20: 7117-7127

111 Fry A. M., Meraldi P. and Nigg E. A. (1998) A centrosomal function for the human Nek2 protein kinase, a member of the NIMA family of cell cycle regulators. EMBO J. 17: 470-481

112 Meraldi P. and Nigg E. A. (2001) Centrosome cohesion is regulated by a balance of kinase and phosphatase activities. J. Cell Sci. 114: 3749-3757

113 Fry A. M., Mayor T., Meraldi P., StierhofY. D., Tanaka K. and Nigg E. A. (1998) C-Nap1, a novel centrosomal coiled-coil protein and candidate substrate of the cell cycle-regulated protein kinase Nek2. J. Cell Biol. 141: 1563-1574

114 Mayor T., Stierhof Y. D., Tanaka K., Fry A. M. and Nigg E. A. (2000) The centrosomal protein C-Nap1 is required for cell cycle-regulated centrosome cohesion. J. Cell Biol. 151: 837-846

115 Fletcher L., Cerniglia G. J., Nigg E. A., Yend T. J. and Muschel R. J. (2004) Inhibition of centrosome separation after DNA damage: a role for Nek2. Radiat Res 162: 128-135

116 Crawford D. F. and Piwnica-Worms H. (2001) The G(2) DNA damage checkpoint delays expression of genes encoding mitotic regulators. J. Biol. Chem. 276: 37166-37177

117 Giet R. and Prigent C. (1999) Aurora/Ipl1p-related kinases, a new oncogenic family of mitotic serine-threonine kinases. J. Cell Sci. 112 (Pt 21): 3591-3601

118 Chan C. S. and Botstein D. (1993) Isolation and characterization of chromosome-gain and increase-in-ploidy mutants in yeast. Genetics 135: 677-691

119 Glover D. M., Leibowitz M. H., McLean D. A. and Parry H. (1995) Mutations in aurora prevent centrosome separation leading to the formation of monopolar spindles. Cell 81: 95105

120 Biggins S., Severin F. F., Bhalla N., Sassoon I., Hyman A. A. and Murray A. W. (1999) The conserved protein kinase Ipl1 regulates microtubule binding to kinetochores in budding yeast. Genes Dev. 13: 532-544

121 Shindo M., Nakano H., Kuroyanagi H., Shirasawa T., Mihara M., Gilbert D. J. et al. (1998) cDNA cloning, expression, subcellular localization, and chromosomal assignment of mammalian aurora homologues, aurora-related kinase (ARK) 1 and 2. Biochem. Biophys. Res. Commun. 244: 285-292

122 Bischoff J. R., Anderson L., Zhu Y., Mossie K., Ng L., Souza B. et al. (1998) A homologue of Drosophila aurora kinase is oncogenic and amplified in human colorectal cancers. EMBO J. 17: 3052-3065

123 Stenoien D. L., Sen S., Mancini M. A. and Brinkley B. R. (2003) Dynamic association of a tumor amplified kinase, Aurora-A, with the centrosome and mitotic spindle. Cell Motil. Cytoskeleton 55: 134-146

124 Krystyniak A., Garcia-Echeverria C., Prigent C. and Ferrari S. (2006) Inhibition of Aurora A in response to DNA damage. Oncogene advance online publication Sept. 12, 2005; doi:10.1038/sj. onc. 1209056

125 Hirota T., Kunitoku N., Sasayama T., Marumoto T., Zhang D., Nitta M. et al. (2003) Aurora-A and an interacting activator, the LIM protein Ajuba, are required for mitotic commitment in human cells. Cell 114: 585-598
126 Sen S., Zhou H. and White R. A. (1997) A putative serine/threonine kinase encoding gene BTAK on chromosome $20 \mathrm{q} 13$ is amplified and overexpressed in human breast cancer cell lines. Oncogene 14: 2195-2200

127 Zhou H., Kuang J., Zhong L., Kuo W. L., Gray J. W., Sahin A. et al. (1998) Tumour amplified kinase STK15/BTAK induces centrosome amplification, aneuploidy and transformation. Nat. Genet. 20: 189-193

128 Carmena M. and Earnshaw W. C. (2003) The cellular geography of aurora kinases. Nat. Rev. Mol. Cell. Biol. 4: 842-854

129 Castro A., Arlot-Bonnemains Y., Vigneron S., Labbe J. C., Prigent C. and Lorca T. (2002) APC/Fizzy-Related targets Aurora-A kinase for proteolysis. EMBO Rep. 3: 457-462

130 Littlepage L. E. and Ruderman J. V. (2002) Identification of a new $\mathrm{APC} / \mathrm{C}$ recognition domain, the $\mathrm{A}$ box, which is required for the Cdh1-dependent destruction of the kinase Aurora-A during mitotic exit. Genes Dev. 16: 2274-2285

131 Castro A., Vigneron S., Bernis C., Labbe J. C., Prigent C. and Lorca T. (2002) The D-Box-activating domain (DAD) is a new proteolysis signal that stimulates the silent D-Box sequence of Aurora-A. EMBO Rep. 3: 1209-1214

132 Littlepage L. E., Wu H., Andresson T., Deanehan J. K., Amundadottir L. T. and Ruderman J. V. (2002) Identification of phosphorylated residues that affect the activity of the mitotic kinase Aurora-A. Proc. Natl. Acad. Sci. USA 99: 15440 15445

133 Walter A. O., Seghezzi W., Korver W., Sheung J. and Lees E. (2000) The mitotic serine/threonine kinase Aurora2/AIK is regulated by phosphorylation and degradation. Oncogene 19: 4906-4916

134 Ferrari S., Marin O., Pagano M. A., Meggio F., Hess D., ElShemerly M. et al. (2005) Aurora-A site specificity: a study with synthetic peptide substrates. Biochem. J. 390: 293-302

135 Grieco D., Porcellini A., Avvedimento E. V. and Gottesman M. E. (1996) Requirement for cAMP-PKA pathway activation by $M$ phase-promoting factor in the transition from mitosis to interphase. Science 271: 1718-1723

136 Haydon C. E., Eyers P. A., Aveline-Wolf L. D., Resing K. A., Maller J. L. and Ahn N. G. (2003) Identification of novel phosphorylation sites on Xenopus laevis Aurora A and analysis of phosphopeptide enrichment by immobilized metalaffinity chromatography. Mol. Cell. Proteomics 2: 1055-1067

137 Crosio C., Fimia G. M., Loury R., Kimura M., Okano Y., Zhou H. et al. (2002) Mitotic phosphorylation of histone H3: spatiotemporal regulation by mammalian Aurora kinases. Mol. Cell. Biol. 22: 874-885

138 Zhao Z. S., Lim J. P., Ng Y. W., Lim L. and Manser E. (2005) The GIT-associated kinase PAK targets to the centrosome and regulates Aurora-A. Mol. Cell 20: 237-249

139 Eyers P. A., Erikson E., Chen L. G. and Maller J. L. (2003) A novel mechanism for activation of the protein kinase aurora a. Curr. Biol. 13: 691-697

140 Kufer T. A., Sillje H. H., Korner R., Gruss O. J., Meraldi P. and Nigg E. A. (2002) Human TPX2 is required for targeting Aurora-A kinase to the spindle. J. Cell Biol. 158: 617-623

141 Bayliss R., Sardon T., Vernos I. and Conti E. (2003) Structural basis of Aurora-A activation by TPX2 at the mitotic spindle. Mol. Cell 12: 851-862

142 Katayama H., Zhou H., Li Q., Tatsuka M. and Sen S. (2001) Interaction and feedback regulation between STK15/BTAK/ Aurora-A kinase and protein phosphatase 1 through mitotic cell division cycle. J. Biol. Chem. 276: 46219-46224

143 Satinover D. L., Leach C. A., Stukenberg P. T. and Brautigan D. L. (2004) Activation of Aurora-A kinase by protein phosphatase inhibitor-2, a bifunctional signaling protein. Proc. Natl. Acad. Sci. USA 101: 8625-8630

144 Kiat L. S., Hui K. M. and Gopalan G. (2002) Aurora-A kinase interacting protein (AIP), a novel negative regulator of human Aurora-A kinase. J. Biol. Chem. 277: 45558-45565 
145 Dutertre S., Cazales M., Quaranta M., Froment C., Trabut V., Dozier C. et al. (2004) Phosphorylation of CDC25B by Aurora-A at the centrosome contributes to the G2-M transition. J. Cell Sci. 117: 2523-2531

146 Ouchi M., Fujiuchi N., Sasai K., Katayama H., Minamishima Y. A., Ongusaha P. P. et al. (2004) BRCA1 phosphorylation by Aurora-A in the regulation of G2 to M transition. J. Biol. Chem. 279: 19643-19648

147 Liu Q., Kaneko S., Yang L., Feldman R. I., Nicosia S. V., Chen J. et al. (2004) Aurora-A abrogation of p53 DNA binding and transactivation activity by phosphorylation of serine 215 . J. Biol. Chem. 279: 52175-52182

148 Marumoto T., Hirota T., Morisaki T., Kunitoku N., Zhang D., Ichikawa Y. et al. (2002) Roles of aurora-A kinase in mitotic entry and G2 checkpoint in mammalian cells. Genes Cells. 7: $1173-1182$

149 Bischoff J. R. and Plowman G. D. (1999) The Aurora/Ipllp kinase family: regulators of chromosome segregation and cytokinesis. Trends Cell Biol. 9: 454-459

150 Yasui Y., Urano T., Kawajiri A., Nagata K., Tatsuka M., Saya H. et al. (2004) Autophosphorylation of a newly identified site of Aurora-B is indispensable for cytokinesis. J. Biol. Chem. 279: $12997-13003$

151 Adams R. R., Wheatley S. P., Gouldsworthy A. M., KandelsLewis S. E., Carmena M., Smythe C. et al. (2000) INCENP binds the Aurora-related kinase AIRK2 and is required to target it to chromosomes, the central spindle and cleavage furrow. Curr. Biol. 10: 1075-1078

152 Bishop J. D. and Schumacher J. M. (2002) Phosphorylation of the carboxyl terminus of inner centromere protein (INCENP) by the Aurora B Kinase stimulates Aurora B kinase activity. J. Biol. Chem. 277: 27577-27580

153 Terada Y., Tatsuka M., Suzuki F., Yasuda Y., Fujita S. and Otsu M. (1998) AIM-1: a mammalian midbody-associated protein required for cytokinesis. EMBO J. 17: 667-676

154 Giet R. and Glover D. M. (2001) Drosophila aurora B kinase is required for histone $\mathrm{H} 3$ phosphorylation and condensin recruitment during chromosome condensation and to organize the central spindle during cytokinesis. J. Cell Biol. 152: 669-682

155 Hsu J. Y., Sun Z. W., Li X., Reuben M., Tatchell K., Bishop D. K. et al. (2000) Mitotic phosphorylation of histone H3 is governed by Ip11/aurora kinase and Glc7/PP1 phosphatase in budding yeast and nematodes. Cell 102: 279-291

156 Goto H., Yasui Y., Nigg E. A. and Inagaki M. (2002) AuroraB phosphorylates Histone $\mathrm{H} 3$ at serine 28 with regard to the mitotic chromosome condensation. Genes Cells 7: 11-17

157 Hendzel M. J., Wei Y., Mancini M. A., Van Hooser A., Ranalli T., Brinkley B. R. et al. (1997) Mitosis-specific phosphorylation of histone $\mathrm{H} 3$ initiates primarily within pericentromeric heterochromatin during G2 and spreads in an ordered fashion coincident with mitotic chromosome condensation. Chromosoma 106: 348-360

158 Van Hooser A., Goodrich D. W., Allis C. D., Brinkley B. R. and Mancini M. A. (1998) Histone H3 phosphorylation is required for the initiation, but not maintenance, of mammalian chromosome condensation. J. Cell Sci. 111 (Pt 23): 3497 3506

159 Fischle W., Tseng B. S., Dormann H. L., Ueberheide B. M., Garcia B. A., Shabanowitz J. et al. (2005) Regulation of HP1chromatin binding by histone $\mathrm{H} 3$ methylation and phosphorylation. Nature doi: 10.1038/nature04219

160 Hirota T., Lipp J. J., Toh B. H. and Peters J. M. (2005) Histone H3 serine 10 phosphorylation by Aurora B causes HP1 dissociation from heterochromatin. Nature doi: 10.1038/nature 04254

161 Ditchfield C., Johnson V. L., Tighe A., Ellston R., Haworth C., Johnson T. et al. (2003) Aurora B couples chromosome alignment with anaphase by targeting BubR1, Mad2, and Cenp-E to kinetochores. J. Cell Biol. 161: 267-280
162 Hauf S., Cole R. W., LaTerra S., Zimmer C., Schnapp G., Walter R. et al. (2003) The small molecule Hesperadin reveals a role for Aurora B in correcting kinetochore-microtubule attachment and in maintaining the spindle assembly checkpoint. J. Cell Biol. 161: 281-294

163 Andrews P. D., Ovechkina Y., Morrice N., Wagenbach M., Duncan K., Wordeman L. et al. (2004) Aurora B regulates MCAK at the mitotic centromere. Dev. Cell 6: 253-268

164 Lan W., Zhang X., Kline-Smith S. L., Rosasco S. E., BarrettWilt G. A., Shabanowitz J. et al. (2004) Aurora B phosphorylates centromeric MCAK and regulates its localization and microtubule depolymerization activity. Curr. Biol. 14: 273-286

165 Ohi R., Sapra T., Howard J. and Mitchison T. J. (2004) Differentiation of cytoplasmic and meiotic spindle assembly MCAK functions by Aurora B-dependent phosphorylation. Mol. Biol. Cell 15: 2895-2906

166 Goto H., Yasui Y., Kawajiri A., Nigg E. A., Terada Y., Tatsuka M. et al. (2003) Aurora-B regulates the cleavage furrow-specific vimentin phosphorylation in the cytokinetic process. J. Biol. Chem. 278: 8526-8530

167 Zeilig C. E., Johnson R. A., Sutherland E. W. and Friedman D. L. (1976) Adenosine 3':5'-monophosphate content and actions in the division cycle of synchronized HeLa cells. J. Cell Biol. 71: 515-534

168 Smith M. E., Dickinson J. R. and Wheals A. E. (1990) Intracellular and extracellular levels of cyclic AMP during the cell cycle of Saccharomyces cerevisiae. Yeast 6: 53-60

169 Grieco D., Avvedimento E. V. and Gottesman M. E. (1994) A role for cAMP-dependent protein kinase in early embryonic divisions. Proc. Natl. Acad. Sci. USA 91: 9896-9900

170 Yamashita Y. M., Nakaseko Y., Samejima I., Kumada K., Yamada H., Michaelson D. et al. (1996) 20S cyclosome complex formation and proteolytic activity inhibited by the cAMP/ PKA pathway. Nature 384: 276-279

171 Ishii K., Kumada K., Toda T. and Yanagida M. (1996) Requirement for PP1 phosphatase and 20S cyclosome/APC for the onset of anaphase is lessened by the dosage increase of a novel gene sds23+. EMBO J. 15: 6629-6640

172 Cass L. A., Summers S. A., Prendergast G. V., Backer J. M., Birnbaum M. J. and Meinkoth J. L. (1999) Protein kinase Adependent and -independent signaling pathways contribute to cyclic AMP-stimulated proliferation. Mol. Cell. Biol. 19: 5882-5891

173 Pinna L. A. and Ruzzene M. (1996) How do protein kinases recognize their substrates? Biochim. Biophys. Acta 1314: 191-225

174 Levin D. E., Fields F. O., Kunisawa R., Bishop J. M. and Thorner J. (1990) A candidate protein kinase C gene, PKC1, is required for the $\mathrm{S}$. cerevisiae cell cycle. Cell 62: 213-224

175 Sun B., Murray N. R. and Fields A. P. (1997) A role for nuclear phosphatidylinositol-specific phospholipase $\mathrm{C}$ in the $\mathrm{G} 2 / \mathrm{M}$ phase transition. J. Biol. Chem. 272: 26313-26317

176 Takai Y., Ogawara M., Tomono Y., Moritoh C., Imajoh-Ohmi S., Tsutsumi O. et al. (1996) Mitosis-specific phosphorylation of vimentin by protein kinase $\mathrm{C}$ coupled with reorganization of intracellular membranes. J. Cell Biol. 133: 141-149

177 Eggert M., Radomski N., Linder D., Tripier D., Traub P. and Jost E. (1993) Identification of novel phosphorylation sites in murine A-type lamins. Eur. J. Biochem. 213: 659-671

178 Shtivelman E., Sussman J. and Stokoe D. (2002) A role for PI 3-kinase and PKB activity in the G2/M phase of the cell cycle. Curr. Biol. 12: 919-924

179 Dangi S., Cha H. and Shapiro P. (2003) Requirement for phosphatidylinositol-3 kinase activity during progression through S-phase and entry into mitosis. Cell. Signal. 15: 667-675

180 Roberts E. C., Shapiro P. S., Nahreini T. S., Pages G., Pouyssegur J. and Ahn N. G. (2002) Distinct cell cycle timing requirements for extracellular signal-regulated kinase and phosphoinositide 3-kinase signaling pathways in somatic cell mitosis. Mol. Cell. Biol. 22: 7226-7241 
181 Alvarez B., Martinez A. C., Burgering B. M. and Carrera A. C. (2001) Forkhead transcription factors contribute to execution of the mitotic programme in mammals. Nature 413: 744-747

182 Kandel E. S., Skeen J., Majewski N., Di Cristofano A., Pandolfi P. P., Feliciano C. S. et al. (2002) Activation of Akt/protein kinase B overcomes a $\mathrm{G}(2) / \mathrm{m}$ cell cycle checkpoint induced by DNA damage. Mol. Cell. Biol. 22: 7831-7841

183 King F. W., Skeen J., Hay N. and Shtivelman E. (2004) Inhibition of Chk1 by activated PKB/Akt. Cell Cycle 3: 634-637

184 Shtivelman E. (2003) Promotion of mitosis by activated protein kinase B after DNA damage involves polo-like kinase 1 and checkpoint protein CHFR. Mol. Cancer Res. 1: 959-969

185 Berry L. D. and Gould K. L. (1996) Regulation of Cdc2 activity by phosphorylation at T14/Y15. Prog. Cell Cycle Res. 2: 99-105

186 Bimbo A., Liu J. and Balasubramanian M. K. (2005) Roles of Pdk1p, a fission yeast protein related to phosphoinositide-dependent protein kinase, in the regulation of mitosis and cytokinesis. Mol. Biol. Cell 16: 3162-3175
187 Toyoshima-Morimoto F., Taniguchi E., Shinya N., Iwamatsu A. and Nishida E. (2001) Polo-like kinase 1 phosphorylates cyclin B1 and targets it to the nucleus during prophase. Nature 410: $215-220$

188 Strogatz S. H. (2001) Exploring complex networks. Nature 410: $268-276$

189 Kitano H. (2004) Biological robustness. Nat. Rev. Genet. 5: 826-837

190 Berman H. M., Westbrook J., Feng Z., Gilliland G., Bhat T. N., Weissig H. et al. (2000) The Protein Data Bank. Nucleic. Acids. Res. 28: 235-242

191 Nowakowski J., Cronin C. N., McRee D. E., Knuth M. W., Nelson C. G., Pavletich N. P. et al. (2002) Structures of the cancer-related Aurora-A, FAK, and EphA2 protein kinases from nanovolume crystallography. Structure (Camb.) 10: 1659-1667

192 Winey M. and Huneycutt B. J. (2002) Centrosomes and checkpoints: the MPS1 family of kinases. Oncogene 21: 6161-6169

\section{(17) To access this journal online: \\ (4P) http://www.birkhauser.ch}

